\title{
Research on the New Way to Promote the Development of Urban Modern Economy - The Development of New Service Industry
}

\author{
Yongyan Yang ${ }^{1, \text { a }}$ \\ ${ }^{1}$ Xi'an International University, Shaanxi, Xi'an, China, 710077 \\ ${ }^{a}$ email,
}

Keywords: Modern Economy; Urban Economic Development; Emerging Services

\begin{abstract}
With the development of economy and society, the shortcomings of traditional industries have become increasingly prominent and the world needs to change the traditional development model to find a more reasonable way, so the emerging service industry came into being. Emerging services have different effects in different areas, and the impact is also gradually increased. In this paper, the new service industry is under the macro background of the modern economy field and explores the relationship between emerging service industry and the urban modern economic development. There are three aspects: First, the advantages of urban emerging services compared with the traditional industries; Second, the role of city emerging service industry on promoting the modern economy; Third, the significance of city emerging service industry on modern economic development. And we concluded that the emerging service industry has an irreplaceable role and significance on the modern economic development, it is the new road to promote the city's modern economic development.
\end{abstract}

\section{Introduction}

Marxist philosophy pointed out that the material in the process of continuous movement, the world is the development of the world, need to look at the development of the eyes of things. The continuous development and progress of the social economy is the general trend of the development of the material world. In the Song Dynasty, the prosperity of the commodity economy reached its peak, forming a wave of economic development climax. Since the Song Dynasty, Chinese economic development is the result of the economic development of the ancient Chinese economy. The economic activities of the people in China are self-sufficient and not for the exchange. The economy began to decline; the occasion of the Ming and Qing Dynasties, the emergence of capitalism, but because of the closed-door policy, the situation is grim, the environment is bad, the development is extremely slow; the late Qing Dynasty, the Western countries of the gunboat bombardment of China closed the door, a large number of industrial products The People's Republic of China in 1949 to set up, but also nearly three decades of turmoil; eventually under the leadership of Comrade Deng Xiaoping, the implementation of reform and opening up, since then, after the collapse of the Chinese economy, the collapse of the small peasant economy; Chinese rapid economic development, to the present 21st century, Chinese change is already earth-shaking.

Chinese economic development has undergone a process of coexistence from agriculture, handicrafts to agriculture, industry and agriculture, industry and services. Agriculture and industry are traditional industries, especially agriculture, the existence of time for thousands of years; industry is also due to national policy support, rapid development; service industry is different, it is emerging industries, it must rely on traditional industries, along with the economy to a certain extent to develop. Compared with the traditional industries, the advantages of emerging services is obvious, but there are also problems: emerging services as a new industry, theoretical preparation and practice based on a lot of deficiencies, do not have to shake the strength of traditional industries; Skeptical or even disagreement about emerging services. Therefore, this paper will explore the advantages of the new service industry compared with the traditional industries, and its role in the promotion of urban modern economic development and its irreplaceable significance to make a corresponding description. 


\section{The Advantages of Urban Emerging Services Compared with the Traditional Industries,}

Compared with Agriculture. Chinese agricultural source can be traced back thousands of years ago, until now are still cannot be ignored in the ring, because agriculture is the development of the existence of the base, there is no agriculture, even now the development of this extremely fast times, The consequences cannot imagine. However, the limitations of agriculture are also very obvious: the need for a lot of resources. The development of agriculture, the need to ensure adequate farmland quantity and the number of labor, human and material resources consumption is great, and the time period is long, the survival efficiency is generally not high. China has always attached importance to agricultural issues, and now also proposed the development of modern agriculture, the concept and policy, the purpose is to improve agricultural efficiency while reducing the consumption of resources, but Chinese actual situation decided, the implementation of this policy is still difficult, the effect remains to be strengthen. Emerging service industry is the use of modern ideas, network technology, new marketing methods, and service innovation developed services. Compared with agriculture, it does not need to produce agricultural products, so it does not need a lot of arable land, but do not need to spend a lot of manpower and material resources, fast, high efficiency.

Speaking of agricultural and emerging service industry comparison, and then look at Chinese industrial and emerging services industry comparison.

Compared with Industry. Chinese industry probably began in the 1860s. Opium war, that is, before the 1940s, China has been implementing a policy of closed-door policy, allowing the business time is very small; even if allowed to trade, only open one or several ports, limited, so Chinese capitalist budding Development is not up, the industry is not there; after the powers to open the door, some officials think that the advanced nature of Western science and technology will help the Qing government to get rid of the powers of control, so in the "division Yi technology to justice" under the influence of thinking, After the founding of the People's Republic of China in 1949, the Chinese government profoundly recognized the important practical significance of industrial development to the country, so the development of the People's Republic of China, after the establishment of the People's Republic of China, Vigorously develop the industry, industry gradually replace agriculture as the key. But the advantages and disadvantages of industrial development is also very obvious, the most cannot be ignored is the industrial development of environmental pollution and resource problems. No one can deny that industrial development, while promoting economic development, has also caused extremely serious environmental pollution and resource consumption and other adverse consequences. The new service industry has five basic characteristics of high human capital content, high technology content, high growth, high risk and high value-added, low dependence on resources and less environmental pollution [1]. Compared with the traditional industries of agriculture and industry, the advantages of emerging services are undoubtedly very prominent, more critical is that it appears, but also change the traditional economic structure, accelerate the optimization and upgrading of industrial structure, is conducive to economic and social science, sustained and coordinated development.

\section{The Role of the City's Emerging Service Industry on Promoting Modern Economy}

Promote the Rapid Economic Development. The world is constantly developing, the development means that new things are constantly producing, the old food is also constantly perish, but whether it is new things or the destruction of old things there is a certain process, not overnight to complete. For the modern economy, the emerging services industry, the emergence of this emerging industry is a challenge, but also an opportunity. Its emergence, to the traditional industry caused a certain impact; but at the same time it also to the dull economic environment into a tonic, because it appears, in fact, has opened up a new economic development path, like thousands of years ago agriculture Appeared, more than 100 years ago, industrial sprouts in general. The following is a sort of out of the emerging service industry on the positive role of economic development: 
The emergence of emerging urban services is bringing a lot of employment opportunities. As a new industry, the emergence of new urban services, will lead to the development of related industries, resulting in a large number of additional employment opportunities can accommodate a huge number of human resources, to a large extent to avoid the waste of talent. This employment opportunity can just fill the gaps in traditional industries, but also can ease the increasingly sharp employment pressure, increase employment channels. In the production of a large number of jobs at the same time, the surrounding industries also will accelerate the development of the formation of a complete industrial chain and the surrounding industry chain.

The emergence of emerging urban services can increase local revenue. The emergence of emerging services, virtually promote the socio-economic development at the same time, there is also a way to increase the local revenue. The economic effect of an industry is not just looking at the surface, but also through the phenomenon to see the essence. The economic benefits of urban emerging service industry, in direct promotion of economic development, to meet the needs of the employment crowd at the same time, to the local, to the country also brought the corresponding fiscal revenue, the state's fiscal revenue from the civilian population, the equivalent of indirect Promote the development of urban economy.

The emergence of emerging urban services can improve the quality of life of the people. Emerging industries rely on existing industries and derived from other related industries, these industries greatly meet the people's growing material and spiritual life needs, enrich and expand the people's daily life, enrich the people's spiritual world, thus improving the quality of life of the people and enhance the people's happiness.

Promote the Healthy, Orderly and Coordinated Development of the Economy. The emergence of emerging urban services has a great impact on the traditional mode of economic development.

With the rapid development of urban emerging service industry, the traditional industrial and agricultural economic development model has changed, and gradually formed a new industrial and agricultural services industry development model. The emergence of this model can improve the economic development structure, to the weak traditional industries into a tonic, on the basis of the industrial structure adjustment and promote the healthy development of the economy.

The emergence of urban emerging services can improve the city's comprehensive competitiveness. The emergence and development of the service industry, to a large extent improve the city function, both to enhance the internal cohesion, but also improve the external influence, virtually enhance the city's comprehensive competitiveness.

The emergence of emerging urban services can promote the development of urban and rural areas. The scope of radiation in urban emerging services is not limited to cities, but rural areas are also affected. Under the guidance of the national scientific development concept, urban and rural development is the fundamental way, the city's emerging service industry to promote the development of the city, will inevitably lead to rural economic development, speed up the modernization of rural construction and promote economic development.

\section{The Significance of the City's Emerging Service Industry on Economic Development}

The emergence of urban emerging service industry is the trend, is the development of the direction, its appearance, whether it is individual, local or national significance is very important.

Change the Traditional Industry Dual Economic Development Model. In addition to a small part of the world's service industry has developed to a considerable degree of developed countries, most other developing countries are still in the agricultural and industrial dual development model, and some agriculture as the most important, and some biased towards industry. China was in the period of rapid development and this period of service has been produced and developed. It appears to change the traditional Chinese dual economic development model, the formation of a ternary and parallel development model, although from the current point of view, the impact of service industry can also be limited, but from some foreign countries experience, The development of emerging services is the only way for the economy to achieve high speed and sustain growth. 
It Is Conducive to Industrial Restructuring and Optimization and Upgrading. Chinese economic growth rate exposes many of Chinese economic structure of the drawbacks, and now China is no longer the pursuit of economic growth but pay more attention to the healthy development of the economy, economic restructuring, industrial structure optimization and upgrading has become the key. Chinese "service industry development," the second Five-Year Plan, "the content pointed out that accelerating the development of service industry is an important way to adapt to the rapid economic development of China is to achieve the goal of Chinese industrial structure optimization and upgrading of important preparations [2]. The emergence and development of urban emerging service industry is conducive to the realization of economic restructuring, promote industrial structure optimization and upgrading, is conducive to the healthy development of modern economy.

\section{Conclusion}

From the ancient small peasant economy self-sufficiency to the rapid development of social economy, the emerging service industry has created a new situation. It can be seen from the text that the city emerging service industry as a new industry, on the one hand, it has obvious advantages compared with the traditional industry is; on the other hand, its emergence also has a great role in promoting the economic development. Moreover, its emergence also has an irreplaceable role and significance on the country's development and social progress. Unfortunately, Chinese service industry as a relatively late start, there are still many deficiencies, its development is far less than developed countries, but China has fully aware of the strategic significance of the service industry, the relevant measures are also improved. I believe in the near future, Chinese service industry will truly become the mainstay of economic and social development.

\section{Acknowledgements}

Fund Project: Shaanxi Provincial Science and Technology Department "Shaanxi Province 2016 Science and Technology Research and Development Plan" project, Research on the Construction of Competitive Evaluation System of Urban Emerging Pilot Service in Shaanxi Province from the Perspective of Internationalization-A Case Study of Xi'an City. Item No: 2016KRM077

\section{References}

[1] Xia Jie long. Chinese emerging service industry development motivation and policy recommendations[J]. Learning and exploration, 2012, 05: 74-78.

[2] Zhang Na. Hebei Province, the service industry to optimize the upgrading of industrial structure to promote the role of [J]. Hebei University of Economics and Trade, 2014, 16(3): 62-67. 